\title{
Design and Development of a Low-Cost, Portable Monitoring Device for Indoor Environment Quality
}

\author{
Akira Tiele $\mathbb{D}$, Siavash Esfahani $(\mathbb{D}$, and James Covington $(\mathbb{D}$ \\ School of Engineering, University of Warwick, Coventry CV4 7AL, UK \\ Correspondence should be addressed to James Covington; j.a.covington@warwick.ac.uk
}

Received 31 August 2017; Revised 10 November 2017; Accepted 25 December 2017; Published 4 March 2018

Academic Editor: Andreas Schütze

Copyright (C) 2018 Akira Tiele et al. This is an open access article distributed under the Creative Commons Attribution License, which permits unrestricted use, distribution, and reproduction in any medium, provided the original work is properly cited.

\begin{abstract}
This article describes the design and development of a low-cost, portable monitoring system for indoor environment quality (IEQ). IEQ is a holistic concept that encompasses elements of indoor air quality (IAQ), indoor lighting quality (ILQ), acoustic comfort, and thermal comfort (temperature and relative humidity). The unit is intended for the monitoring of temperature, humidity, PM2.5, PM10, total VOCs $(\times 3), \mathrm{CO}_{2}$, CO, illuminance, and sound levels. Experiments were conducted in various environments, including a typical indoor working environment and outdoor pollution, to evaluate the unit's potential to monitor IEQ parameters. The developed system was successfully able to monitor parameter variations, based on specific events. A custom IEQ index was devised to rate the parameter readings with a simple scoring system to calculate an overall IEQ percentage. The advantages of the proposed system, with respect to commercial units, is associated with better customisation and flexibility to implement a variety of low-cost sensors. Moreover, low-cost sensor modules reduce the overall cost to provide a comprehensive, portable, and real-time monitoring solution. This development facilities researchers and interested enthusiasts to become engaged and proactive in participating in the study, management, and improvement of IEQ.
\end{abstract}

\section{Introduction}

The indoor environment plays a critical role in our wellbeing due to the amount of time we spend indoors. The European Commission estimates that Europeans spend around $90 \%$ of their time in closed surrounds, mainly at home or in the workplace [1]. It is therefore unsurprising that our everyday surroundings have the power to drastically influence our health in a positive or negative way. Indoor environments can be two to five times more toxic than the outdoors [2]. For instance, up to 20\% of Europeans suffer from asthma due to substances inhaled indoors. Tobacco smoke, asbestos, radon, and benzene released inside buildings have been identified as key contributors to the increases in EU cancer cases [1]. In 2014, the World Health Organization (WHO) announced that air pollution is the world's largest single environmental health risk, after an estimated 7 million people died (one in eight of total global deaths) in 2012 as a result of air pollution exposure [3]. Studies have linked indoor air quality (IAQ) to mental health and illnesses that are not easily noticeable in the short-term but could be major concerns in the long-term [4]. The vast majority of air pollution deaths are attributed to cardiovascular diseases, such as strokes, ischemic heart disease, and chronic obstructive pulmonary disease (COPD). Moreover, new research has established a link between air pollution and increased mental illness in children. The results suggest that higher concentrations of air pollution, first and foremost from traffic, may increase psychiatric disorders in children and adolescents [5]. Air pollution is currently monitored by environmental or government authorities using static monitoring stations, which are equipped with instruments for measuring regulatory pollutants. The air pollutant analysers are relatively bulky, heavy, and expensive, with price ranges between $€ 5000$ and $€ 30,000$ [6]. A significant amount of resources are also required to routinely maintain and calibrate them [7].

The growing concern about IAQ has resulted in the development of various indoor environment quality(IEQ-) monitoring systems. IEQ is a holistic concept, encompassing elements of IAQ, indoor lighting quality (ILQ), acoustic comfort, and thermal comfort (temperature and 
relative humidity). Together with ventilation and airconditioning systems, these factors affect the health, comfort, and performance of occupants. The two most common methods of improving indoor air quality are increasing the ventilation rate, which in turn reduces air pollutants, and reducing the sources of pollutants directly [8]. Other approaches include replacing outdated appliances and introducing filtering systems. However, to identify sources of poor IEQ and evaluate the effectiveness of improvement strategies, chemical and physical monitoring is needed. Moreover, monitoring systems of this nature are needed for everyday users to become engaged and proactive in participating in the management and improvement of the environmental quality at home.

Recent developments to improve the monitoring of IEQ parameters include smart objects, which can manage and control the occupant's surroundings. This involves "hacking" common objects, such as fans or desk lamps, to make them capable of carrying out smart operations to improve the comfort of the indoor environment [9]. Others have used gas sensors to construct a miniature electronic nose (eNose), which can detect poisonous organic vapours indoors [10]. Combining multiple sensors into one unit means for more broadly assessing conditions relating to adverse health effects, such as hazardous gaseous substances, and conditions more affecting the comfort and well-being of residents or workers. Many of these parameters are interesting when considering the development of "smart homes" and a higher level of automation regarding household appliances.

A number of EU-funded projects, including SENSIndoor, EuNetAir, and IAQSense, have focused on realising selective, low-ppb measurement low-cost gas sensors, with quite promising results. The outcomes of these projects include novel sensor systems, real-time monitors, VOC sensor systems, preconcentrators, air quality modelling, and standardised methods [11-13]. However, these call for a deeper understanding of sensor operation and read-out, which cannot necessarily be obtained with off-the-shelf electronic modules. Projects such as Multi Sensor Platform (MSP) have successfully put together a variety of sensors into a micromechanic approach to provide novel methods of monitoring IEQ parameters. These developments are likely to encourage institutions, researchers, and businesses to take a greater interest in the advancements and trends in IAQrelated research.

Efforts have also been made to design sophisticated monitoring systems, which utilize artificial neural networks (ANN) to classify the sources influencing IAQ in various indoor environments [14]. Personalised mobile sensing systems are also on the rise, with the development of a portable indoor location-tracking sensor that uses carbon dioxide measurements to determine accurate personal-proximity IAQ readings [15].

For households and small businesses, there is a limited variety of commercially available air quality-monitoring devices, including some industrial-grade equipment and consumer-grade app-enabled devices. Industrial monitors tend to measure individual parameters with greater precision. The prices of consumer products range from $£ 150$ to
$£ 400$, depending on their measurement capabilities and features. Popular "all-round" products, such as Foobot (Airboxlab S.A.S., USA) and Awair (Bitfinder, USA), measure temperature, humidity, VOCs, and PM2.5. These products do not provide a comprehensive monitoring solution for other important parameters relating to IEQ. Furthermore, these devices are not portable, since they require constant connection to a mains plug. The occupant is therefore limited to only monitoring easily accessible areas. Lastly, many of these products do not provide real-time readings. Instead, intermittent hourly reports are generated and sent to the phone app. Real-time readings are critical for applications in evacuation or air cleaner systems [16].

In addition to personal monitoring devices, some community-led air quality-sensing networks have been established. Prominent examples include the Air Quality Egg (Wicked Device, USA) and the Smart Citizen Platform (Acrobotic Industries, USA). The concept involves Wi-Fienabled hardware, which acts as a network node to measure and share IEQ data. The user can then track their personal environment using a phone app or log in to the platform to engage with the wider community. While this model provides an interesting method of large-scale urban IEQmonitoring, the costs of setting up network nodes is likely to be unaffordable for most households. At $\$ 280$ per Air Quality Egg, \$1400 would have to be spent in order to provide a comprehensive monitoring node [17]. Based on these findings, the system proposed in this article has been designed to reduce the cost for a comprehensive unit, which offers a portable and real-time monitoring solution for IEQ. In addition, it provides details of how units can be constructed out of existing commercially available sensors.

\section{Materials and Methods}

In the past few years, with rising levels of smog in China, PM2.5 (particulate matter less than 2.5 micrometres in diameter) and volatile organic compounds (VOCs) have become key indicators for indoor air quality. However, there are various other parameters involved with the monitoring of IEQ. Previous research into IAQ systems commonly targeted carbon dioxide $\left(\mathrm{CO}_{2}\right)$, ozone $\left(\mathrm{O}_{3}\right)$, carbon monoxide $(\mathrm{CO})$, oxygen $\left(\mathrm{O}_{2}\right)$, nitrogen dioxide $\left(\mathrm{NO}_{2}\right)$, temperature, and humidity [14].

Approaches to monitoring indoor pollutants frequently involve the use of individual sensors and/or sensors cards or the design of a custom system-on-chip (SoC). Sensor cards do not provide the desired flexibility of selecting a comprehensive mix of sensors. Moreover, customising an IEQ SoC is associated with extraordinarily high design and fabrication costs. The production technique and cost is often closely related to the required production volume. It is unlikely that research groups or interested enthusiasts can afford to produce a custom SoC for small-volume development projects.

Therefore, most research systems use the first option, whereby individual sensors are assembled into a system. In part, this could be considered similar to an electronic nose (the so-called eNose). In our case, this approach was also used. 
The aim was to design a system able to operate as a rechargeable and portable unit, which measures indoor air pollutants via low-cost sensor modules. Our selected sensors were interfaced with a microcontroller development board (Feather M0) to process the measured signals and determine the IEQ status in real time. The system was designed to store raw data onto a microSD card for subsequent processing and analysis. The values are also printed to a low-power OLED display, which provides the user with constant feedback. Internal ventilation within the device is created by a microfan. To provide the most comprehensive monitoring of IEQ parameters, an array of ten sensors was implemented. A list of sensors and manufacturers is given in Table 1.

For sensor flexibility, two SPEC sensors have been incorporated into the design to enable certain system modifications. The SPEC sensor range shares an identical PCB footprint, which makes it possible and convenient to exchange sensors, based on application needs. The CO and IAQ sensors can therefore be swapped for 6 other sensors, such as ozone $\left(\mathrm{O}_{3}\right)$, nitrogen dioxide $\left(\mathrm{NO}_{2}\right)$, sulphur dioxide $\left(\mathrm{SO}_{2}\right)$, hydrogen sulphide $\left(\mathrm{H}_{2} \mathrm{~S}\right)$, breath alcohol, and respiratory irritants.

Three TVOC sensors are deployed within the IEQmonitoring unit. They operate on the principle of MEMS metal oxide semiconductor- (MOS-) sensing technology by correlating $\mathrm{CO}_{2}$ readings with measured TVOC levels. $\mathrm{CO}_{2}$ is widely used as a measure for indoor air quality, since people are the principal source of $\mathrm{CO}_{2}$ in an indoor environment. Algorithms are used to directly correlate $\mathrm{CO}_{2}$ with TVOC levels. The limitation of this approach is that any secondary or unexpected VOC sources can result in false readings. These sensors have been developed to replace more expensive NDIR sensors in building automation and heating, ventilation, and air-conditioning applications. However, the cost of $\mathrm{CO}_{2}$ sensors is rapidly dropping. While these sensors are known for their lack of accuracy, multiple sensors can be used in an eNose approach to gain more information about different VOC contaminants.

Details of sensor module names, measurement ranges, and accuracy are summarised in Table 2 . The system diagram for the IEQ-monitoring device is shown in Figure 1.

The manufacture and assembly of the prototype was completed in two stages. A custom PCB was created using Altium Designer (Altium, USA), based on the system diagram shown in Figure 1. Thereafter, the PCB was placed inside an electronics enclosure and connected to the other internal components, such as the fan and display. Free PCB design tools, such as Eagle (Autodesk, USA), can also be used by interested enthusiasts to design a PCB, suitable for their needs. The assembly stages are shown in Figure 2.

The cost of the sensor modules is under $£ 150$. With the inclusion of the electronics enclosure, microcontroller, microSD card reader, real-time clock, and OLED display, the hardware costs per unit is about $£ 200$. The sensor system is made up of commercial prototyping boards, which simply need to be plugged into the PCB. This allows researchers and interested enthusiasts to easily replicate a similar set-up. The following section discusses the individual sensing parameters and their respective impacts on IEQ.
2.1. Temperature and Humidity. UK/EU and US law do not state minimum or maximum temperatures in a workplace; however, at least $16^{\circ} \mathrm{C}$ is generally suggested [18]. Moreover, the WHO recommends $24^{\circ} \mathrm{C}$ as the maximum temperature for working in comfort [19]. Both very low or high relative humidity can cause physical discomfort, as the relative humidity of air directly affects temperature perception [20]. Very low (below 20\%) relative humidities can also cause eye irritation [21]. High-humidity environments have a lot of vapour in the air, which prevents the exportation of sweat from the skin and should therefore be avoided [22]. Relative humidity levels between 40 and $70 \%$ do not have a major impact on thermal comfort. However, humidity levels beyond this threshold can increase the incidence of respiratory infections and allergies [20]. In combination with high temperatures, indoor humidity levels also lead to the growth of mould.

2.2. Particulate Matter. There are two categories of particle matter: the first are coarse dust particles between 2.5 and 10 micrometres $(\mu \mathrm{m})$ in diameter, known as PM10. Examples of PM10 particles include dust, pollen, and mould. The second category includes fine particles with diameters of $2.5 \mu \mathrm{m}$ or less, known as PM2.5. PM2.5 particles are produced from solid fuel combustion and industrial processes. In the US, the 24-hour average maximum level for PM2.5 is $35 \mu \mathrm{g}$ per cubic metre $\left(\mu \mathrm{g} / \mathrm{m}^{3}\right)$ and $12 \mu \mathrm{g} / \mathrm{m}^{3}$ as an annual average. For PM10, the short-term limit is $150 \mu \mathrm{g} / \mathrm{m}^{3}$. There is currently no long-term standard [23]. In the UK/EU, the annual average exposure for PM2.5 and PM10 should not exceed the limits of $25 \mu \mathrm{g} / \mathrm{m}^{3}$ and $40 \mu \mathrm{g} / \mathrm{m}^{3}$, respectively [24]. A cohort study by the American Cancer Society tracked 1.2 million American adults for 26 years (1982-2008) and discovered that the mortality of lung cancer increased by $15-27 \%$ when PM2.5 air concentrations increased by $10 \mu \mathrm{g} / \mathrm{m}^{3}$ [25].

2.3. Total Volatile Organic Compounds. Volatile organic compounds (VOCs) are of concern as both indoor and outdoor air pollutants. Common VOCs include trichloroethylene, benzene, toluene, alcohols, and acrolein. VOCs are mostly reported as total VOC (TVOC) readings. This term recognises the combined effect of compounds that may not otherwise have been captured, due to low concentration levels. A low TVOC value usually indicates that there is no VOC problem; however, a high TVOC value may result from a high level of a single compound or from a vast collection of low compound levels [26]. Major contributors to TVOC levels in residences are household products, tobacco smoke, deodorants, and building materials. The health effects of high TVOC concentrations include nausea, dizziness, eye irritation, headaches, and fatigue [27]. Sources indicate that TVOC concentrations between 50 and $325 \mathrm{ppb}$ are acceptable and should not exceed $500 \mathrm{ppb}$ [28].

2.4. Carbon Dioxide. Carbon dioxide $\left(\mathrm{CO}_{2}\right)$ is classed as a substance hazardous to health in Europe. At room temperature and atmospheric pressure, it is a colourless, nonflammable, and odourless gas. However, $\mathrm{CO}_{2}$ is considered toxic in high concentrations, as well as an asphyxiate gas. Increased 
TABLE 1: Sensors deployed within the IEQ-monitoring unit.

\begin{tabular}{lccc}
\hline Product & Type & Manufacturer & Operating principle \\
\hline SHT31 & Temperature \& humidity & Sensirion & CMOS technology \\
HPMA115S0 & Particulate matter & Honeywell & Laser-based light scattering \\
CCS811 & Total VOC (TVOC1) & AMS & Metal oxide gas sensor \\
iAQ-Core C & Total VOC (TVOC2) & AMS & Micromachined MOS technology \\
MiCS-VZ-89TE & Total VOC (TVOC3) & SGX Sensortech & MOS technology \\
T6713 & CO $_{2}$ & Amphenol & Nondispersive infrared (NDIR) \\
LLC 110-102 & CO & SPEC Sensors & Amperometric gas sensor \\
LLC 110-801 & Indoor air quality & SPEC Sensors & Amperometric gas sensor \\
TSL2561 & Illuminance (light) & TAOS & Infrared-responding photodiode \\
Adafruit \#1063 & Microphone & Adafruit & Electret microphone with amplifier \\
\hline
\end{tabular}

TABLE 2: Sensor module names, measurement ranges, and accuracy.

\begin{tabular}{lccc}
\hline Type & Module & $\begin{array}{c}\text { Measurement } \\
\text { range }\end{array}$ & Accuracy \\
\hline Temperature & SHT31 & $0-100 \%$ & $\pm 2 \% \mathrm{RH}$ \\
Humidity & SHT31 & -40 to $125^{\circ} \mathrm{C}$ & $\pm 0.3^{\circ} \mathrm{C}$ \\
PM2.5/PM10 & HPMA115S0 & $0-1000 \mu \mathrm{g} / \mathrm{m}^{3}$ & $\pm 15 \%$ \\
$\begin{array}{l}\text { Total VOC } \\
\text { (TVOC1) }\end{array}$ & CCS811 & $0-1200 \mathrm{ppb}$ & N/A \\
$\begin{array}{l}\text { Total VOC } \\
\text { (TVOC2) }\end{array}$ & iAQ-Core C & $125-600 \mathrm{ppb}$ & N/A \\
$\begin{array}{l}\text { Total VOC } \\
\text { (TVOC3) }\end{array}$ & MiCS-VZ-89TE & $0-1000 \mathrm{ppb}$ & $\mathrm{N} / \mathrm{A}$ \\
$\begin{array}{l}\text { CO } 2 \\
\text { CO }\end{array}$ & T6713 & $0-5000 \mathrm{ppm}$ & $\pm 25 \mathrm{ppm}$ \\
$\begin{array}{l}\text { Indoor air quality } \\
\text { Illuminance } \\
\text { (light) }\end{array}$ & LLC $110-102$ & $0-1000 \mathrm{ppm}$ & $\pm 2 \mathrm{ppm}$ \\
$\begin{array}{l}\text { Microphone } \\
\text { Lil0-801 }\end{array}$ & $0-100 \mathrm{ppm}$ & $\pm 2 \mathrm{ppm}$ \\
\hline
\end{tabular}

concentration levels can lead to irritation of the eyes, nose, and throat. $\mathrm{CO}_{2}$ levels between 350 and 1000 ppm are typical for occupied indoor spaces with good air exchange. The UK/ EU and US long-term exposure limit (8-hour time-weighted average) is $5000 \mathrm{ppm}[29,30]$.

2.5. Carbon Monoxide. Carbon monoxide (CO) is a poisonous, colourless, odourless, and tasteless gas. Common sources include tobacco smoke, engine exhausts, and improperly vented appliances. Average levels in UK homes, without gas stoves, vary from 0.5 to 5 parts-permillion (ppm). Levels near properly adjusted gas stoves are often 5-15 ppm and those near poorly adjusted stoves may be 30 ppm or higher [31]. Acute health effects at high concentrations can include dizziness, headaches, nausea, cardiovascular effects, and death [32]. In the UK/EU and US, long-term levels should remain below 9 ppm [24, 33].

2.6. Illuminance. Poor workplace illumination is associated with ill-health effects, ranging from eye strain, headaches, and fatigue to postural problems and musculoskeletal disorders (MSDs). Dark or dimly lit workplaces can also lead to serious injuries or fatalities. There are no statutory workplace-lighting levels in the UK/EU; however, the HSE suggests that offices and workspaces should have an average illuminance of 200-500 lux for activities relating to writing, reading, and typing. These levels should not drop below 100 lux [34]. Recommended levels in the US vary from 75 to 500 lux.

2.7. Sound Levels. Sound levels are measured in decibels $(\mathrm{dB})$ and are commonly associated with the acoustic comfort of occupants in buildings. There is a direct relationship between acoustic comfort and occupant productivity in commercial buildings [35]. The neutral sound pressure level for aural comfort in typical air-conditioned offices was found to be between 45 and $70 \mathrm{~dB}$, with a mean of $57.5 \mathrm{~dB}$ [36]. For an 8 -hour duration of exposure at the workplace, sound levels should not exceed the upper threshold of 65-80 dB [37].

Based on the guidelines stated above, Table 3 represents a summary of the IEQ index developed to indicate whether the readings are expected ambient levels or associated with health risks.

Some highly relevant indoor gas components like formaldehyde or benzene are not included in the proposed IEQ unit. There are a very limited number of low-cost, off-theshelf gas sensors that can provided the necessary accuracy and sensitivity to measure these parameters. Further research and development activities are required to test and compare commercially available options, in order to include these parameters in future iterations of the IEQ unit.

2.8. Sensor Calibration. Sensor systems in safety-critical applications must undergo rigorous testing to calibrate sensors to their target gases. This device is not intended for safety-critical applications; however, some basic calibration tests were undertaken. This is quite difficult for TVOC levels and particulate matter, as synthesis and systematic variation of these parameters exceed the complexity and funding available for the development of the device. Moreover, it is unlikely that small research groups or interested enthusiasts will have the means to repeat the necessary calibration procedures.

The temperature, humidity, and $\mathrm{CO}_{2}$ readings for the developed IEQ unit were calibrated using a commercially 


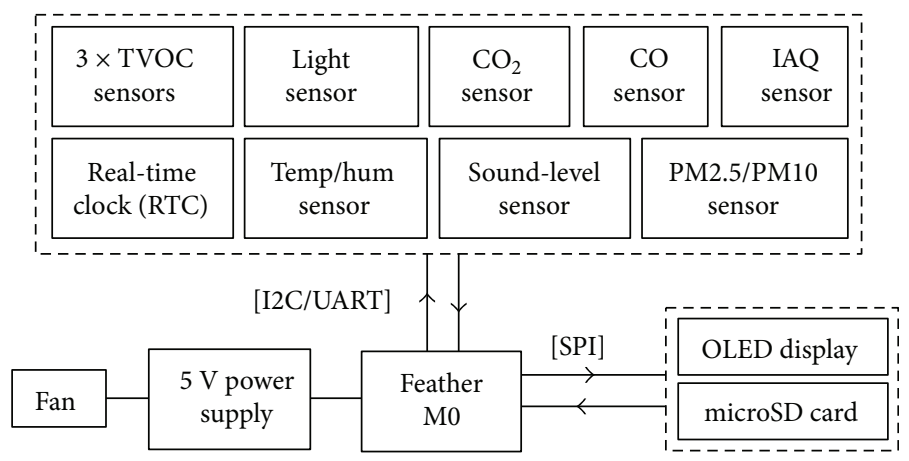

FIGURE 1: IEQ-monitoring device-system diagram.

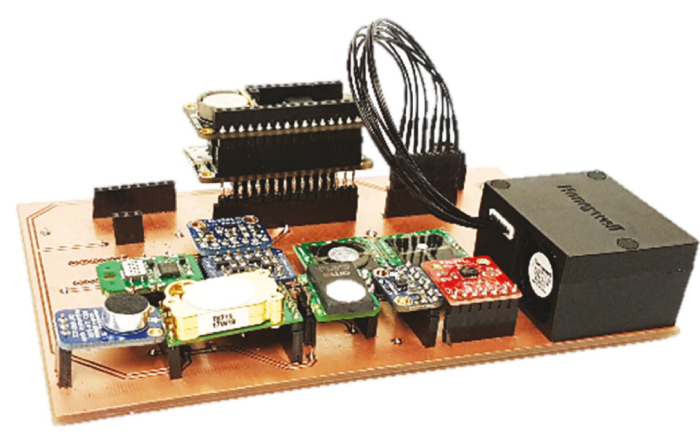

(a)

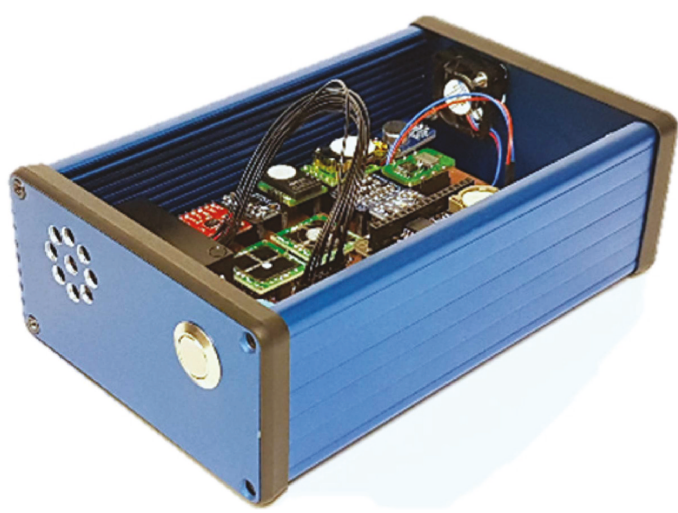

(b)

FIGURE 2: IEQ-monitoring device assembly stages: (a) sensor modules mounted on a custom PCB and (b) assembled prototype with internal connections.

TABLE 3: IEQ index with parameters.

\begin{tabular}{lcc}
\hline IEQ parameter & Ambient levels & Health risk levels \\
\hline Humidity & $40-70 \%$ & $70>H>40 \%$ \\
Temperature & $16-24^{\circ} \mathrm{C}$ & $24>T>16^{\circ} \mathrm{C}$ \\
PM2.5 & $<35 \mu \mathrm{g} / \mathrm{m}^{3}$ & $>35 \mu \mathrm{g} / \mathrm{m}^{3}$ \\
$\mathrm{PM} 10$ & $<150 \mu \mathrm{g} / \mathrm{m}^{3}$ & $>150 \mu \mathrm{g} / \mathrm{m}^{3}$ \\
Total VOC & $50-325 \mathrm{ppb}$ & $>500 \mathrm{ppb}$ \\
$\mathrm{CO}_{2}$ & $350-1000 \mathrm{ppm}$ & $>5000 \mathrm{ppm}$ \\
$\mathrm{CO}$ & $0-10 \mathrm{ppm}$ & $>10 \mathrm{ppm}$ \\
Illuminance & $200-500 \mathrm{lux}$ & $<100 \mathrm{lux}$ \\
Sound levels & $0-70 \mathrm{~dB}$ & $>80 \mathrm{~dB}$ \\
\hline
\end{tabular}

available measurement system (CO210, Extech, USA). This unit uses maintenance-free NDIR $\mathrm{CO}_{2}$ sensors and retails for $£ 250$. An automatic baseline calibration was completed prior to testing. The CO210 and IEQ unit were left in the laboratory environment for 1 hour to stabilise. There was no human activity in the laboratory for this duration. The recorded temperature, humidity, and $\mathrm{CO}_{2}$ levels are shown in Table 4.

The results from this calibration test indicate that the values from the IEQ unit are slightly lower than the "actual" values, measured using the CO210. The temperature and $\mathrm{CO}_{2}$ readings are not within the uncertainty boundaries, stated by the manufacturers. Based on these differences, the temperature and $\mathrm{CO}_{2}$ readings from the IEQ unit were adjusted by $1.9^{\circ} \mathrm{C}$ and $70 \mathrm{ppm}$, respectively.

2.9. Baseline Calibration. To better understand the baseline characteristics of the IEQ unit, the device was place inside an enclosure, along with the CO210, and exposed to zero air. Zero air is synthetic air, commonly used as a carrier gas. It is filtered to contain less than $0.1 \mathrm{ppm}$ of total hydrocarbons. The zero-air generator flowrate was set to $500 \mathrm{ml} /$ min. The devices were placed inside a sealed plastic enclosure, with approximate dimensions of $220 \mathrm{~mm}(L) \times$ $180 \mathrm{~mm}(W) \times 280 \mathrm{~mm}(H)$. The volume of the enclosure is therefore about 11 litres. Once the IEQ unit had stabilised, the zero-air gas line was connected to the enclosure inlet. Some IEQ parameters, such as temperature, light, and sound remained unchanged (as expected). The results of the other parameters are shown in Figures 3-7.

Some interesting characteristics were observed during this baseline calibration. IEQ parameters PM2.5, PM10, humidity, and $\mathrm{CO}_{2}$ behave as expected, demonstrating a steep decline. Temperature, humidity, and $\mathrm{CO}_{2}$ readings closely matched those of the $\mathrm{CO} 210$, indicating that these parameters had been calibrated successfully. PM10, humidity, and $\mathrm{CO}_{2}$ do not reach 0 levels; however, this is likely due to enclosure leakage. Interestingly, the three TVOC 
TABLE 4: IEQ unit temperature, humidity, and $\mathrm{CO}_{2}$ calibration.

\begin{tabular}{lccc}
\hline Parameter & Extech CO210 & IEQ unit & CO210- IEQ \\
\hline Temperature & $23.2^{\circ} \mathrm{C}$ & $21.3^{\circ} \mathrm{C}$ & $+1.9^{\circ} \mathrm{C}$ \\
Humidity & $31.2 \%$ & $31.0 \%$ & $+0.2 \%$ \\
$\mathrm{CO}_{2}$ & $480 \mathrm{ppm}$ & $410 \mathrm{ppm}$ & $+70 \mathrm{ppm}$ \\
\hline
\end{tabular}

sensors have distinctly different readings, when exposed to the same environment.

The minimum measurement read-out of TVOC2 is $125 \mathrm{ppb}$. This value could actually be $0 \mathrm{ppb}$, in agreement with TVOC1. However, this cannot be confirmed and must be assumed to be between 0 and $125 \mathrm{ppb}$. TVOC3 has a minimum read-out of $0 \mathrm{ppb}$, so the baseline value of approximately $240 \mathrm{ppb}$ does not concur with TVOC1 or TVOC2. According to the manufacturer, these sensors are calibrated to a "typical" TVOC mixture, in an indoor environment. If the ratio of compounds in the environment is significantly different, the TVOC output will be affected, as some VOC compounds will have a greater or lesser effect on the sensor. TVOC3 is calibrated based on isobutylene-equivalent levels. If the other sensors were not calibrated using the same reference gas, the responses are unlikely to match. These results also seem to indicate that the zero-air gas line in our laboratory expels some VOCs that cannot be detected by TVOC1 or TVOC2 but respond to TVOC3. The CO and IAQ sensors did not respond to the zero-air exposure, indicating that the sensors had already settled to baseline levels.

2.10. IEQ Index. An IAQ index is a number used by government agencies to communicate to the public how polluted air currently is or is forecasted to become [38]. The index shown in Table 2 represents an improvement compared to a typical IAQ index, since additional factors influencing IEQ have also been taken into consideration. These indexes are useful since it is difficult for nonexpert users to identify how polluted the air is or what the pollution criteria might be. It has been argued that IAQ-monitoring devices should have the capability to notify users about the current air quality using an intuitive display, for example, simple colour-coded descriptions (good, moderate, unhealthy, very unhealthy) that can indicate the air quality level in real-time [16].

For the IEQ-monitoring system proposed in this article, a simple IEQ index indicator has been developed. Readings associated with ambient levels are classified as "good" or "average," depending on whether they fall into the lower or upper half of the previously defined ambient levels. For temperature, the upper half of ambient levels will be considered "good," while lower values will be considered "average." IEQ parameter readings exceeding ambient levels will be classified as "poor" or "bad." Values that slightly exceed the limits of ambient levels will be classified as "poor." These are often values that lie between ambient levels and health risk levels. Health risk levels are considered "bad." The IEQ index scoring system is summarised in Tables 5 and 6.

The $30 \%$ allocated to total VOCs is distributed equally amongst the three sensors. Based on the four IEQ categories, the percentage distribution can be summarised as $10 \%$ for thermal comfort, $10 \%$ for ILQ, $10 \%$ for acoustic comfort, and $70 \%$ to IAQ.

The IEQ score assumes a perfect score of $100 \%$. For this scenario to be true, all IEQ parameters need to fall within the "good" boundaries, stated in Table 5. If any parameter is not "good," the following calculation is completed to determine the impact on the overall IEQ score: the perfect IEQ score is reduced by the IEQ impact of the parameter, multiplied by the associated scoring impact. This is shown below:

$$
\begin{aligned}
\text { IEQ score }= & 100 \%-[(\text { Para. } 1 \text { impact } \% \times \text { scoring impact }) \\
& -(\text { Para. } 2 \text { impact } \% \times \text { scoring impact })-\cdots] .
\end{aligned}
$$

As shown in Table 6, there are 12 IEQ parameters (referred to as Parameter number). The individual parameters are assessed, based on their score and impact, to determine the overall IEQ score. This calculation can be further explained using an example. If the lights turn off, the illuminance reading will drop to below 100 lux and will be categorised "bad." The IEQ impact of illuminance is $10 \%$. The scoring impact of "bad" is 1.0. If this is the only IEQ parameter that is not "good," the IEQ score is simply calculated:

$$
\begin{aligned}
& \text { IEQ score }=100 \%- {[(\text { Para.11(Illuminance }) \text { impact } \%} \\
&\quad \times \text { scoring impact })] \\
&=100 \%-[(10 \% \times 1.0)] \\
&=100 \%-10 \%=90 \% .
\end{aligned}
$$

Based on this scoring system, if all parameters are "good," the IEQ score is $100 \%$. If all parameters were considered average, the IEQ score would be $80 \%$. If all readings are "poor," the IEQ score is $50 \%$. Finally, if all the measurements are categorised as "bad," the IEQ score would be $0 \%$. These categories have been divided into IEQ indicators, as shown in Table 7 . These are also displayed to the user with the IEQ percentage.

This scoring system is quite simplistic but serves as a starting point for further development. There are various factors to consider; for example, the IEQ impact factors may need to be adjusted to follow a ranking based on potential health risks. Moreover, the sampling period, to determine whether a parameter is "good," "average," "poor," or "bad," plays a critical role. Short-term exposure limits are often calculated using 1-hour periods; however, users are likely to favour more frequent updates.

A sampling period of 10 minutes was used here. Readings from individual IEQ parameters will therefore be averaged over a period of 10 minutes. The overall IEQ score is then calculated and displayed to the user. The display also indicates which parameters are causing the IEQ to be lower, along with an associated (A), (P), or (B) rating, for "average," "poor," and "bad," respectively.

The fully assembled IEQ-monitoring device is shown in Figure 8. Two IEQ scores are shown on the display in Figure 9, including a perfect IEQ score and a 90\% IEQ score affected by "bad" indoor lighting quality, following on from the previous example. 


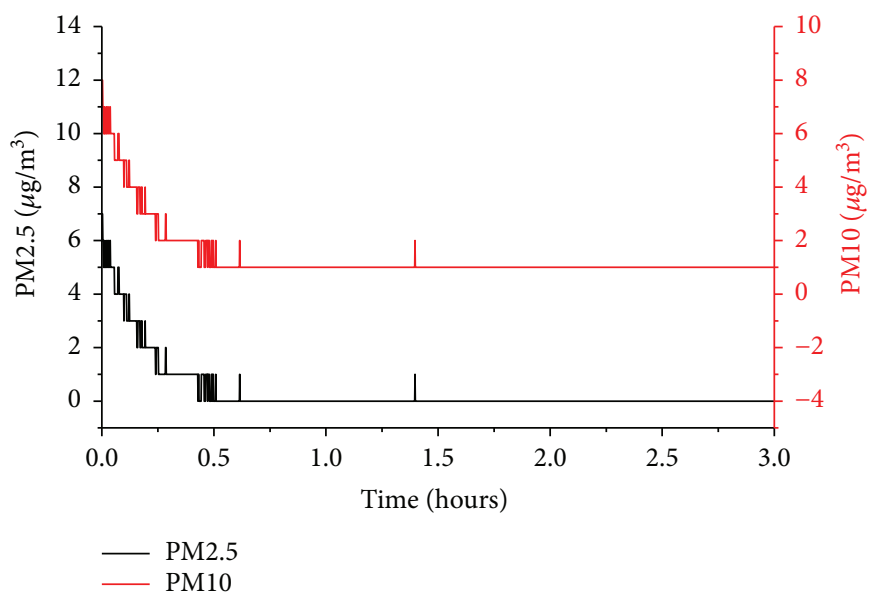

Figure 3: Zero-air baseline-PM2.5 and PM10.

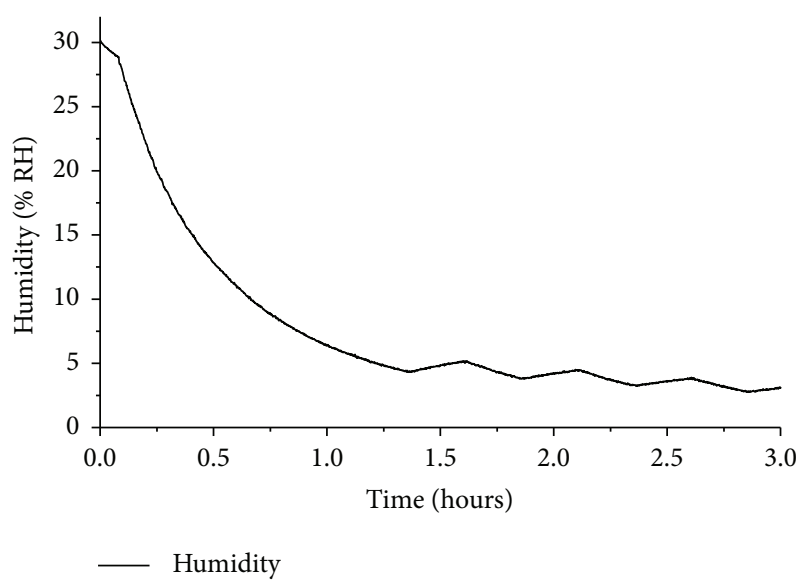

FIgURe 4: Zero-air baseline-humidity.

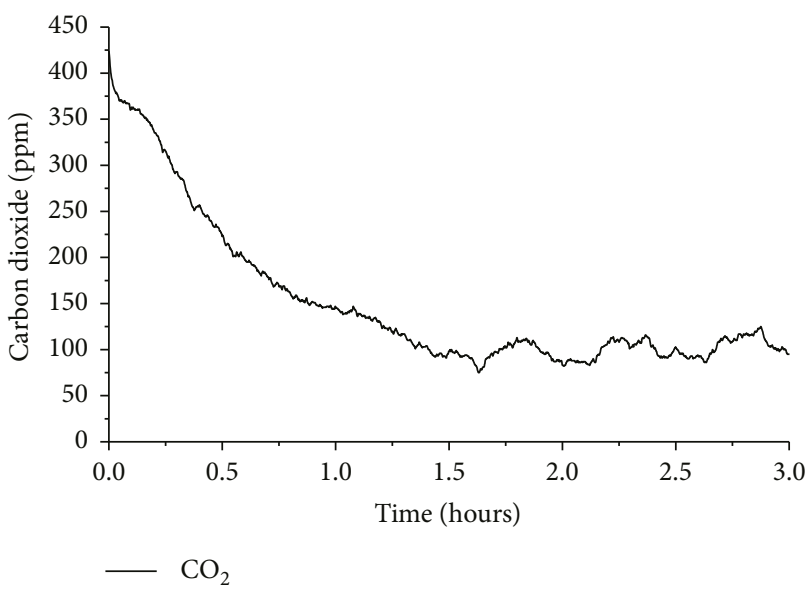

FIgURE 5: Zero-air baseline-carbon dioxide.

2.11. Electronics Enclosure and Battery Life. The dimensions of the electronics enclosure measure $(L) 165 \mathrm{~mm} \times(W)$ $105 \mathrm{~mm} \times(H) 55 \mathrm{~mm}$. The total mass of the device is about $570 \mathrm{~g}$ with batteries and $430 \mathrm{~g}$ without. An airing vent, with an enclosed mesh, has been machined into the top plate of the enclosure. The TSL2561 illuminance (light) sensor has been placed directly below the mesh to provide adequate exposure to ambient light. The side panel shown in Figure 8 conceals a microfan, which provides internal ventilation.

A key advantage of the proposed IEQ-monitoring device is that it can be powered either using a standard mains plug or using a rechargeable battery. The device is therefore portable and can be placed in locations and environments that are usually less accessible. The battery life of a device can be calculated from the input current rating, in milliampere hour (mAh), of the battery and the load current of the system. The unit is powered with a $10,000 \mathrm{mAh}$ power bank. The device's maximum load current was measured to be approximately $103 \mathrm{~mA}$. The battery life of the proposed IEQmonitoring unit is therefore estimated at 68 hours. This includes a 0.7 reduction factor, which has been included to consider allowances for external factors, which may also affect battery life [39]. Nonetheless, this estimate is likely to be exaggerated, since the Feather M0 requires a minimum input voltage. As the power bank discharges, the USB supply voltage will drop below $5 \mathrm{~V}$. Eventually, the voltage will be insufficient to power the device. Taking this limitation into account, 48 hours of continuous operation is a more realistic estimate. The system was able to operate for approximately 60 hours, with intermittent use, over several days.

\section{Results}

Three experiments were conducted to evaluate the unit's potential to monitor IEQ parameters, including chemical presence (air freshener), outdoor pollution, and simulated human activity.

3.1. Chemical Presence. The experiments were conducted at the School of Engineering (University of Warwick). The system was placed in a medium-sized office/laboratory, located in the basement of the building. The office usually has five occupants during working hours. The office has no windows; however, ceiling lights provide illumination and an airconditioning system operates continuously for ventilation. 


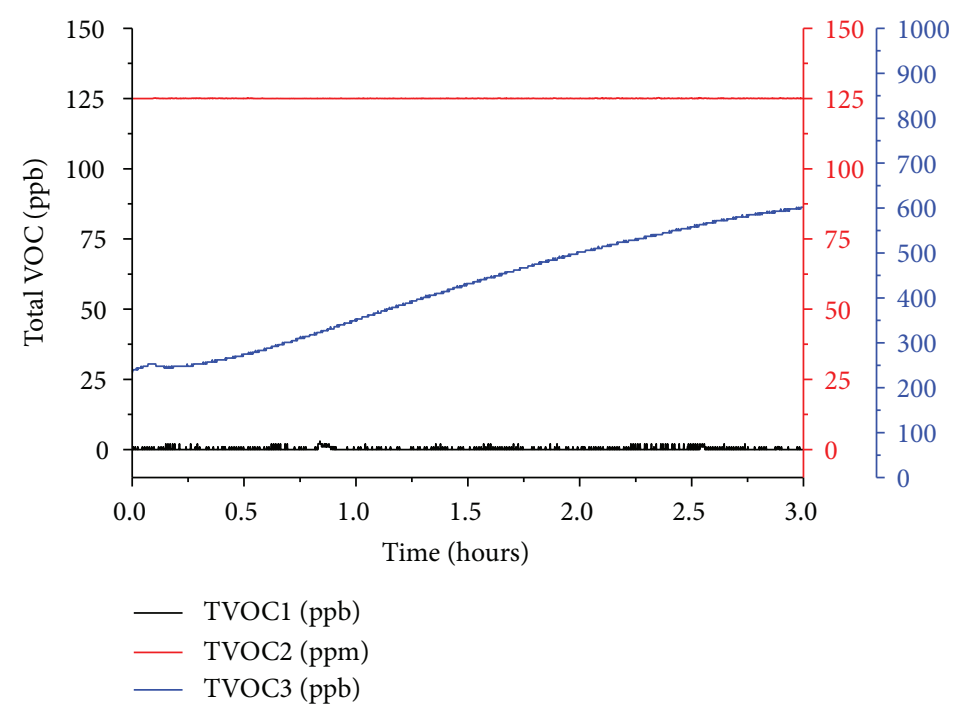

FIgURE 6: Zero-air baseline-total VOCs.

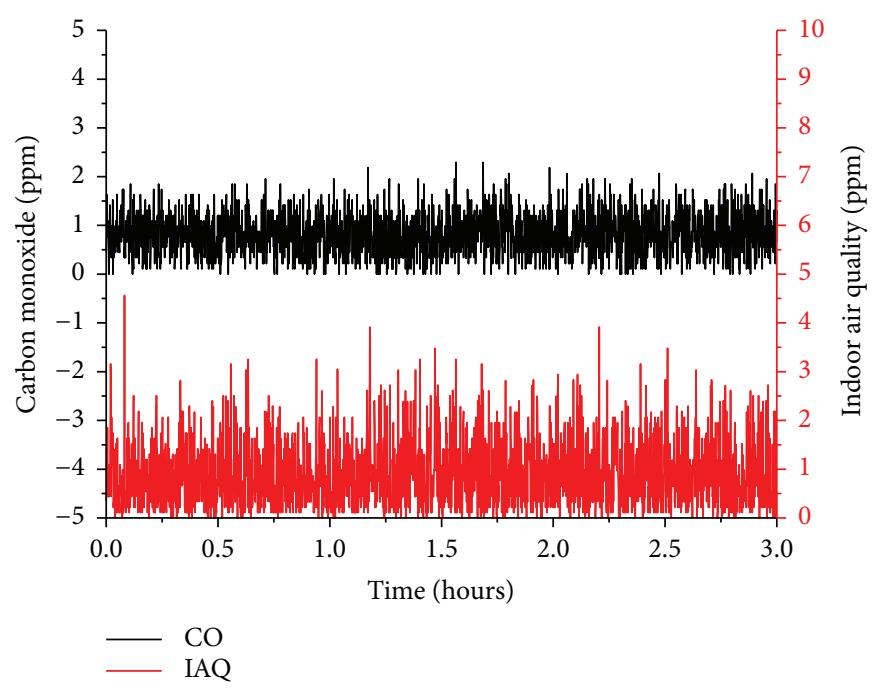

Figure 7: Zero-air baseline-carbon monoxide and indoor air quality.

TABle 5: IEQ index scoring system.

\begin{tabular}{lcccc}
\hline IEQ parameter & "Good" & "Average" & "Poor" & "Bad" \\
\hline Humidity & $40-50 \%$ & $50-60 \%$ & $60-70 \%$ & $70>H>40 \%$ \\
Temperature & $20-24^{\circ} \mathrm{C}$ & $16-20^{\circ} \mathrm{C}$ & $24-26^{\circ} \mathrm{C}$ & $26>T>16^{\circ} \mathrm{C}$ \\
PM2.5 & $0-10 \mu \mathrm{g} / \mathrm{m}^{3}$ & $10-15 \mu \mathrm{g} / \mathrm{m}^{3}$ & $15-35 \mu \mathrm{g} / \mathrm{m}^{3}$ & $>35 \mu \mathrm{g} / \mathrm{m}^{3}$ \\
PM10 & $0-50 \mu \mathrm{g} / \mathrm{m}^{3}$ & $50-80 \mu \mathrm{g} / \mathrm{m}^{3}$ & $80-150 \mu \mathrm{g} / \mathrm{m}^{3}$ & $>150 \mu \mathrm{g} / \mathrm{m}^{3}$ \\
Total VOC & $0-200 \mathrm{ppb}$ & $200-350 \mathrm{ppb}$ & $350-500 \mathrm{ppb}$ & $>500 \mathrm{ppb}$ \\
$\mathrm{CO}_{2}$ & $350-500 \mathrm{ppm}$ & $500-1000 \mathrm{ppm}$ & $1000-5000 \mathrm{ppm}$ & $>5000 \mathrm{ppm}$ \\
$\mathrm{CO}$ & $0-3 \mathrm{ppm}$ & $3-8 \mathrm{ppm}$ & $25-50 \mathrm{ppm}$ & $>10 \mathrm{ppm}$ \\
Indoor air quality & $0-10 \mathrm{ppm}$ & $10-25 \mathrm{ppm}$ & $100-200 \mathrm{lux}$ & $70-80 \mathrm{~dB}$
\end{tabular}


TABLE 6: IEQ parameter impact and category.

\begin{tabular}{lccc}
\hline $\begin{array}{l}\text { Parameter } \\
\text { number }\end{array}$ & $\begin{array}{c}\text { IEQ } \\
\text { parameter }\end{array}$ & $\begin{array}{c}\text { IEQ impact } \\
(\%)\end{array}$ & IEQ category \\
\hline 1 & Humidity & 5 & Thermal comfort \\
2 & Temperature & 5 & Thermal comfort \\
3 & PM2.5 & 5 & Indoor air quality \\
4 & PM10 & 5 & Indoor air quality \\
5 & TVOC1 & 10 & Indoor air quality \\
6 & TVOC2 & 10 & Indoor air quality \\
7 & TVOC3 & 10 & Indoor air quality \\
8 & $\mathrm{CO}_{2}$ & 10 & Indoor air quality \\
9 & $\mathrm{CO}$ & 10 & Indoor air quality \\
10 & Indoor air & 10 & Indoor air quality \\
& quality & & Indoor lighting \\
11 & Illuminance & 10 & quality \\
12 & Sound levels & 10 & Acoustic comfort \\
\hline
\end{tabular}

TABLE 7: IEQ user feedback.

\begin{tabular}{lc}
\hline IEQ score range $(\%)$ & IEQ indicator \\
\hline $0-40$ & Bad \\
$40-60$ & Poor \\
$60-70$ & Below average \\
$70-80$ & Average \\
$80-90$ & Above average \\
$90-100$ & Good \\
\hline
\end{tabular}

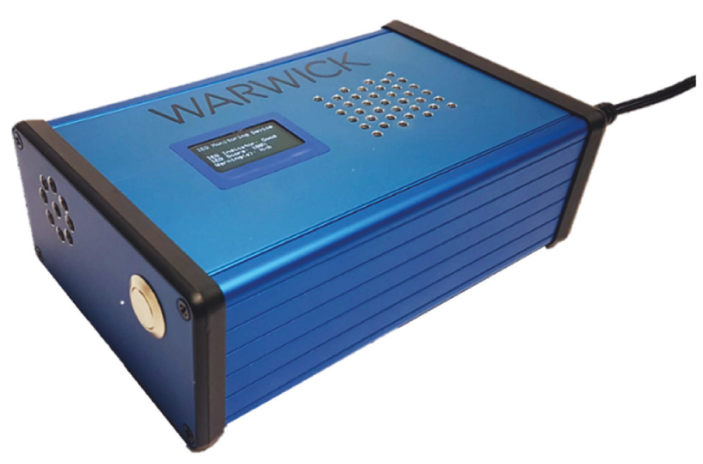

FIGURE 8: Fully assembled IEQ-monitoring device.

It has been suggested that monitoring devices should be positioned at a height between 75 and $120 \mathrm{~cm}$, to occupy a space that is considered a breathing zone for the occupants [40]. The device was therefore placed on a desk, directly in front of one of the occupant's work areas.

A commercially available spraying air freshener was used to expose the IEQ system to chemical presence. These products are advertised to release bursts of fragrance to neutralise odours. These types of air fresheners have widespread use in workplaces, schools, homes, and so forth. However, they can emit and generate a range of potentially hazardous air pollutants. From an IAQ perspective, air fresheners have been indicated as a primary source of volatile organic compounds within buildings [41]. This particular unit could be set to automatically spray fragrance in 9-, 18-, or 36-minute intervals. The air freshener was set to spray at 9-minute intervals. Some IEQ parameters, such as temperature, humidity, light, and sound remained constant. $\mathrm{CO}_{2}$ showed only little variation. The results from this experiment are shown in Figures 10 and 11.

Three fragrance "events" are clearly visible in the sensor responses. The CO and IAQ sensors did not show any response, resembling Figure 7 from the baseline calibration experiment. The sampling period, to calculate the average readings, was 10 minutes. Table 8 provides a summary of the average readings for each IEQ parameter, pre- and postfragrance event, along with the associated indicator.

Based on the readings and indicators shown in Table 7, the IEQ score was calculated. TVOC3 is the only parameter that is not "good." The IEQ score for the period $15-25 \mathrm{~min}$ is therefore $98 \%$. The IEQ score for $25-35 \mathrm{~min}$ includes "poor" PM2.5, "average" TVOC1, and "bad" TVOC3. The overall IEQ score for this period is therefore

$$
\begin{aligned}
\text { IEQ score }= & 100 \%-2.5 \%[\text { PM2 } .5]-2 \%[\text { TVOC } 1] \\
& -10 \%[\text { TVOC } 3]=100 \%-14.5 \%=85.5 \% .
\end{aligned}
$$

The use of air fresheners has caused the overall IEQ in the office to reduce by $12.5 \%$. Two occupants were seated in the office environment during the chemical exposure experiment. Both stated that the perceived fragrance was "very strong" for the first 5 minutes after release. The following 4 minutes were described as "pleasant." However, the fragrance was then released again, due to the setting of the 9-minute release timer, which produced another burst of fragrance, and so on. The subsequent fragrance events were also rated with an overall IEQ score of $85.5 \%$, which is slightly above average. The user feedback from this experiment is shown in Figure 12.

3.2. Outdoor Pollution. Despite the significant changes from the TVOC sensors in the chemical presence test, the CO and IAQ sensors showed little response. This is likely due to the higher measurement range of the SPEC sensors (ppm versus $\mathrm{ppb}$ ). An additional experiment was therefore conducted to demonstrate the sensors' potential to monitor their respective IEQ parameters. The IEQ device was relocated to the exit of a multistorey carpark, at the University of Warwick. The experiment was conducted in the late afternoon, as a number of vehicles were exiting the carpark. Some parameters, such as temperature, humidity, and light remained constant. The results from the CO, IAQ, and TVOC sensors are shown in Figures 13 and 14.

Four distinct contamination "events" are visible in the sensor responses. These occur after about 3, 4, 7, and 7.5 minutes. The TVOC sensors indicate that there was another event after 6 minutes which was not registered by the $\mathrm{CO}$ and IAQ sensors. We can confirm that there were actually five vehicles that exited the carpark during the given timeframe. The first two events involved cars stopping near the device 


\section{IEQ Monitoring Device}

\section{IEQ Indicator: Good \\ IEQ Score: 100\% Warning(s): N/A}

\section{IEQ Monitoring Device}

\section{IEQ Indicator: Good \\ IEQ Score: 90\% \\ Warning(s): \\ Illuminance (A)}

(a)

(b)

FIGURE 9: IEQ scores on OLED display: (a) 100\% IEQ score; (b) 90\% IEQ score.

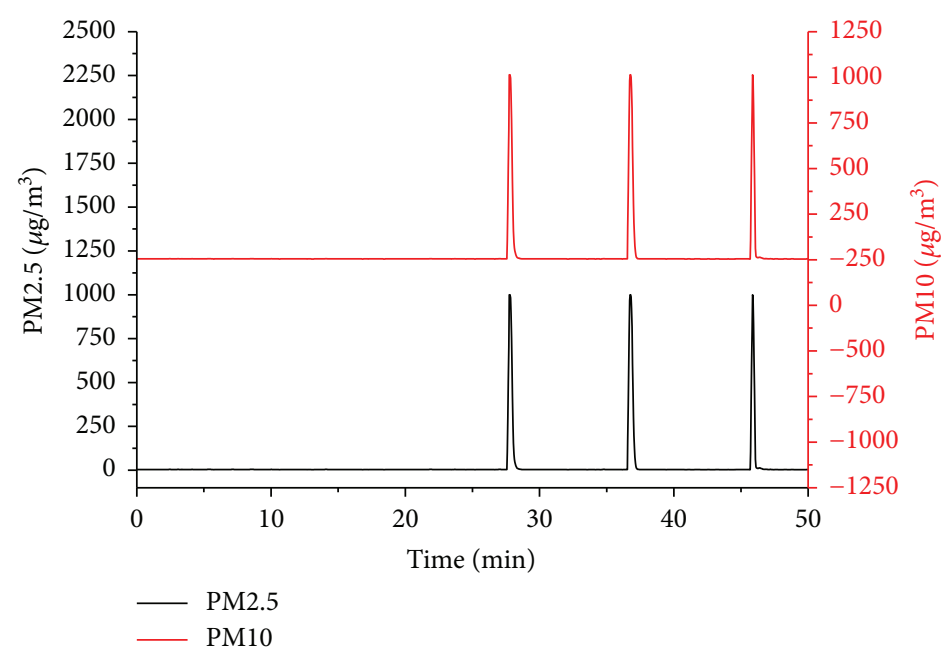

Figure 10: Chemical presence-PM2.5 and PM10.

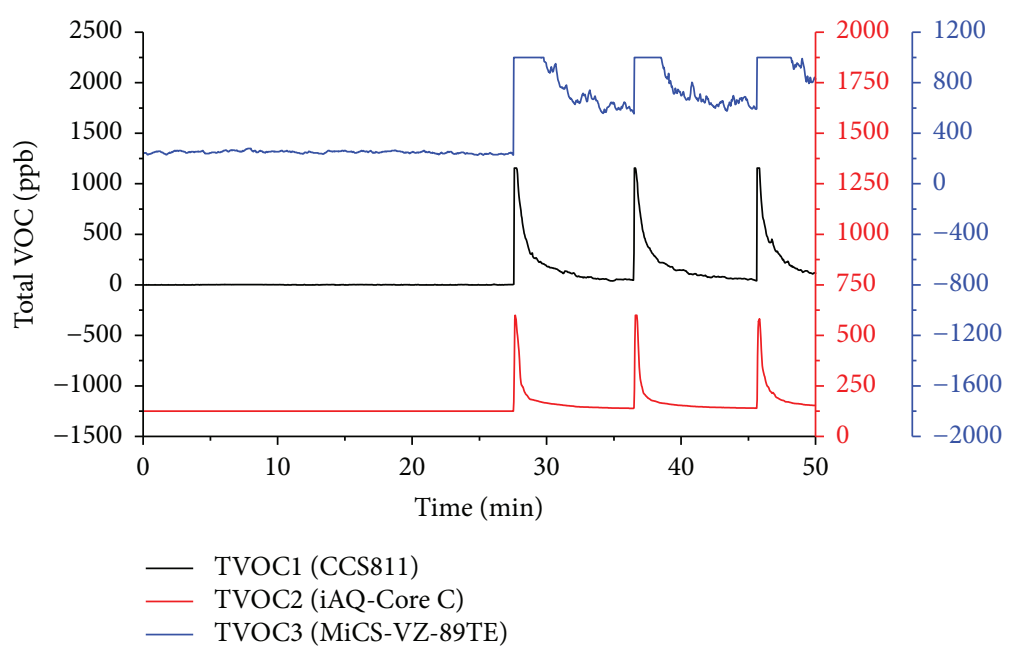

FIgURE 11: Chemical presence-total VOCs.

for a longer time, waiting for a gap to join the flow of traffic. Events at 7 and 7.5 minutes were cars that could join the traffic immediately and did not need to stop and wait. The event at 6 minutes was a motorcycle, passing quickly, which may explain why this event does not appear as a response on the less sensitive CO and IAQ sensors. 
TABLE 8: Chemical presence IEQ parameter results.

\begin{tabular}{lcccc}
\hline IEQ parameter & $\begin{array}{c}\text { Average } \\
\text { reading } \\
(15-25 \mathrm{~min})\end{array}$ & Indicator & $\begin{array}{c}\text { Average } \\
\text { reading } \\
(25-35 \mathrm{~min})\end{array}$ & Indicator \\
\hline Humidity & $40.0 \%$ & Good & $41.3 \%$ & Good \\
Temperature & $23.4^{\circ} \mathrm{C}$ & Good & $23.5^{\circ} \mathrm{C}$ & Good \\
PM2.5 & $4 \mu \mathrm{g} / \mathrm{m}^{3}$ & Good & $38 \mu \mathrm{g} / \mathrm{m}^{3}$ & Poor \\
PM10 & $5 \mu \mathrm{g} / \mathrm{m}^{3}$ & Good & $40 \mu \mathrm{g} / \mathrm{m}^{3}$ & Good \\
TVOC1 & $0 \mathrm{ppb}$ & Good & $202 \mathrm{ppb}$ & Average \\
TVOC2 & $126 \mathrm{ppb}$ & Good & $173 \mathrm{ppb}$ & Good \\
TVOC3 & $248 \mathrm{ppb}$ & Average & $765 \mathrm{ppb}$ & Bad \\
CO 2 & $433 \mathrm{ppm}$ & Good & $418 \mathrm{ppm}$ & Good \\
CO & $1 \mathrm{ppm}$ & Good & $1 \mathrm{ppm}$ & Good \\
IAQ & $1 \mathrm{ppm}$ & Good & $1 \mathrm{ppm}$ & Good \\
Illuminance & $315 \mathrm{lux}$ & Good & $312 \mathrm{lux}$ & Good \\
Sound levels & $23 \mathrm{~dB}$ & Good & $23 \mathrm{~dB}$ & Good \\
\hline
\end{tabular}

\section{IEQ Monitoring Device} IEQ Indicator: AlooveIEQ Score: $85.5 \%$ Warning(s): PHe.5(P), TUOC1 $(A)$, TUOC3 $(B)$

FIgURE 12: IEQ score following exposure to air fresheners.

3.3. Simulated Human Activity. The previous experiments have established that the majority of sensors show promising results to potentially monitor their respective IEQ parameters. This had not yet been demonstrated for sound levels and illuminance. A separate experiment was conducted to validate these parameters. To show a realworld example of variations of sound and light, a lecture scenario was created. This involved setting up a speaker system, placing the IEQ unit inside a medium-sized lecture room and adjusting the light conditions. For 30 minutes, the lights were left on and the room was silent. Thereafter, the lights were dimmed and a recorded lecture was played to the room. After 30 minutes, the lights were turned back on and the recording was stopped. The results from experiment are shown in Figure 15.

The audio recording could be heard clearly. During the first 10 minutes, the average sound level was approximately $53 \mathrm{~dB}$, which is considered "average." The average light level was 25 lux, which is considered "bad." During this period, the overall IEQ score was $88 \%$, which is above average.

\section{Discussion}

The sensor responses shown in Figures 10 and 11 and 13-15 demonstrate that the system shows the potential to monitor variations in IEQ parameters and calculate an IEQ score, based on a 10-minute averaging period. In Figures 11 and 14, the TVOC sensors show different magnitudes of responses, in terms of ppb; however, they generally align in terms of responding to specific events. This indicates that their sensitivities to VOCs are not the same. It is therefore necessary to include all three of these sensors, in order to better understand the mixtures of VOCs in different environments. As shown during the baseline calibration experiment, some sensors may not respond to certain VOCs, while others do.

Figure 13 shows the IAQ sensor reading saturating at 100 ppm; however, it did not even exceed 1 ppm during the indoor chemical exposure experiment. It seems that this sensor is more sensitive to contaminants that are expelled from motor vehicles than to those released in the chemical experiment. Further experiments are required to identify which indoor pollutants can be measured using this sensor.

This article focuses on the processes associated with the design, development, and manufacture of an IEQmonitoring device. The IEQ score refers to a simple lookup table and may be deemed too simplistic, due to the complex interplay and correlations between various IEQ parameters. Longer tests (day or weeks) will be conducted in the future, to analyse the unit's reliability to follow long-term variations in IEQ parameters and how this may affect the overall IEQ. However, some additional instrumentation will be necessary to provide accurate reference data. The sampling period of 10 minutes can also be increased or decreased to monitor variations of parameters over different time periods.

There are many factors relating to human senses that cannot be adequately considered in this context. For example, apart from average illuminance, colour (temperature/ continuous spectrum) and modulation are important aspects that should be taken into account. Moreover, apart from mean sound levels in $\mathrm{dB}$, variations, peaks, and weighting are important quantitative features to consider. One fundamental problem of acoustics is relating physical measures of sound to subjective impressions. Perceived noise (PN) levels may not align with acquired readings. Methods of estimating PN include weighted sums over frequency bands; however, further work and advanced audio-processing expertise are required to investigate this limitation.

Similarly, state-of-the-art ASHRAE standards have not been considered, regarding temperature and humidity. The CBE thermal comfort tool includes parameter control of the following factors: air temperature, mean radiant temperature, air speed, humidity, metabolic rate, and clothing, to determine compliance with ASHREA-55 standards for acceptable thermal environments. Further work and design activities are required to investigate these parameters and include them in the IEQ index.

\section{Conclusions}

This article described the design and development of a lowcost, portable, battery-powered monitoring device for indoor environment quality (IEQ). The use of commercially 


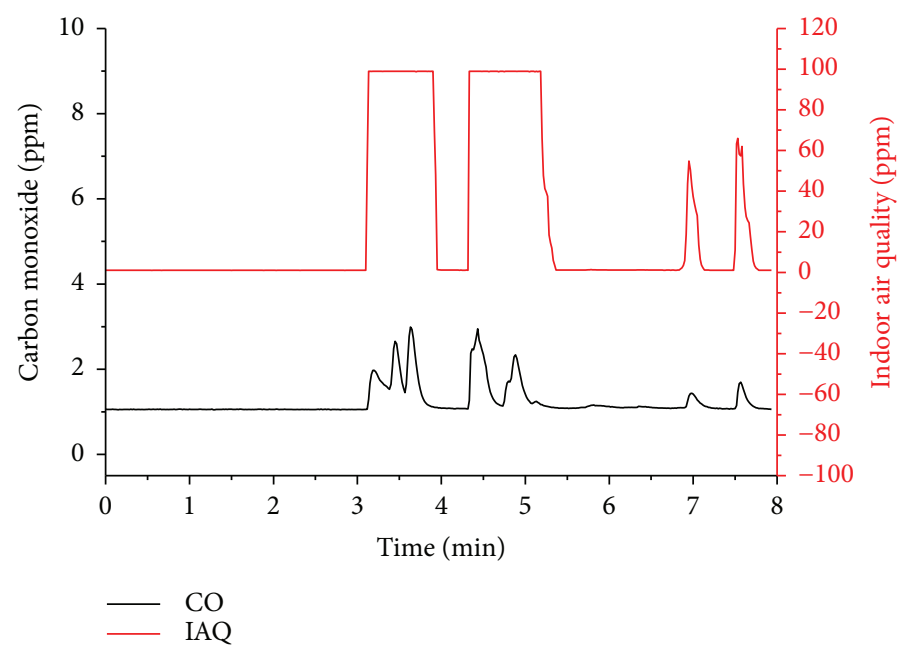

FIgURE 13: Outdoor pollution—carbon monoxide and IAQ.

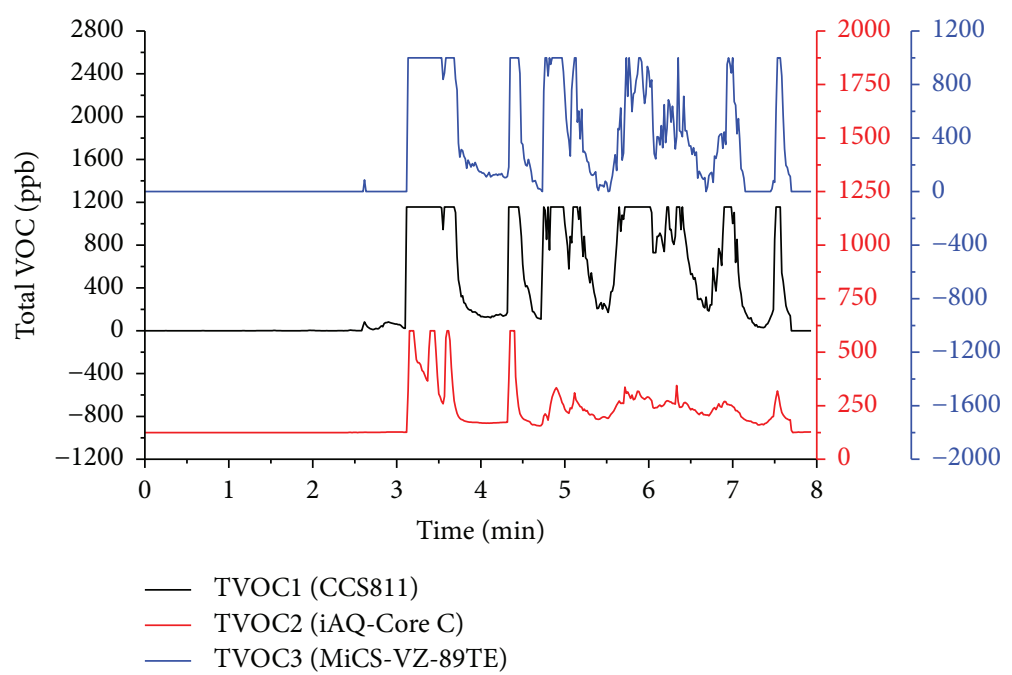

FIGURE 14: Outdoor pollution-total VOCs.

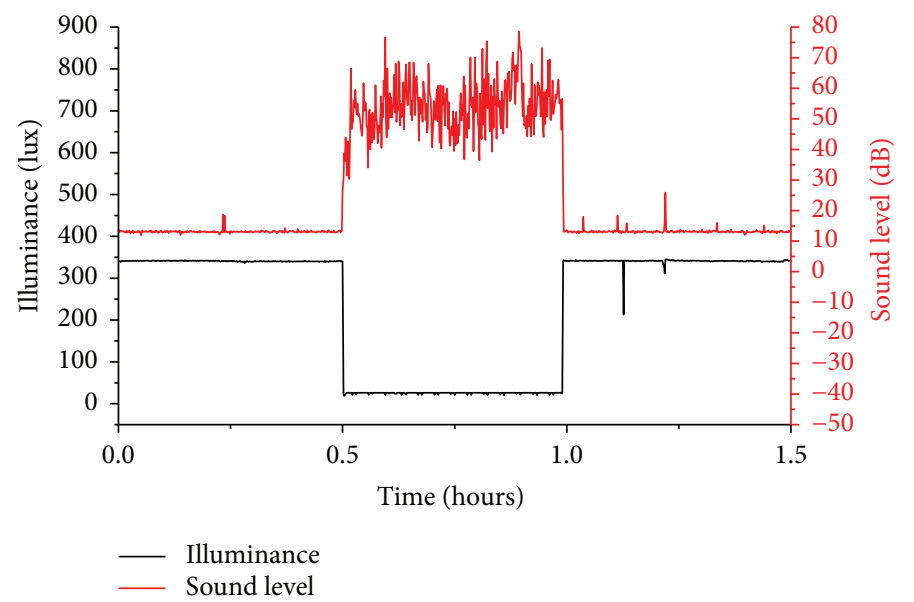

FIGURE 15: Simulated human activity-illuminance and sound levels. 
available low-cost sensors and a do-it-yourself (DIY) approach provided the fastest and most efficient development of the prototype. The unit monitors temperature, humidity, PM2.5, PM10, TVOC ( $\times 3), \mathrm{CO}_{2}$, CO, IAQ, illuminance, and sound levels. A custom IEQ index was developed to rate the recorded measurements with a scoring system to calculate an overall IEQ percentage.

The potential of this system was confirmed and demonstrated by experiments conducted in various environments, including exposure to a typical indoor working environment (air fresheners, lighting, and sound) and outdoor air pollution. The device was successfully able to record variations in IEQ parameters. The advantages of the proposed system, with respect to commercial alternatives, is associated with fast prototyping, better customisation, and flexibility to implement a variety of low-cost sensors. Moreover, lowcost sensor modules minimise the cost to provide a comprehensive, portable, and real-time monitoring solution, for less than $£ 200$. Our future efforts are now focused on further reducing the size of the system and deploying them in pollution- and agricultural-monitoring applications. A concise, simple, and repeatable calibration strategy will be developed in preparation for this work. This development is intended to facilitate researchers, enthusiasts or everyday users to become engaged and proactive in participating in the study, management, and improvement of IEQ.

\section{Conflicts of Interest}

The authors declare that there are no conflicts of interest regarding the publication of this paper.

\section{References}

[1] European Commission, Indoor Air Pollution: New EU Research Reveals Higher Risks than Previously Thought, June 2017, http://europa.eu/rapid/press-release_IP-03-1278_en.htm.

[2] EPA, The Inside Story: A Guide to Indoor Air Quality, June 2017, https:/www.epa.gov/indoor-air-quality-iaq/insidestory-guide-indoor-air-quality.

[3] WHO, 7 Million Premature Deaths Annually Linked to Air Pollution, June 2017, http://www.who.int/mediacentre/news/ releases/2014/air-pollution/en/.

[4] I. Houtman, M. Douwes, T. De Jong et al., New Forms of Physical and Psychosocial Health Risks at Work, European Parliament, Brussels, 2008.

[5] A. Oudin, L. Bråbäck, D. O. Åström, M. Strömgren, and B. Forsberg, "Association between neighbourhood air pollution concentrations and dispensed medication for psychiatric disorders in a large longitudinal cohort of Swedish children and adolescents," BMJ Open, vol. 6, article e010004, no. 6, 2016.

[6] N. Castell, F. R. Dauge, P. Schneider et al., "Can commercial low-cost sensor platforms contribute to air quality monitoring and exposure estimates?," Environment International, vol. 99, pp. 293-302, 2017.

[7] C. Y. Chong and S. P. Kumar, "Sensor networks: evolution, opportunities, and challenges," Proceedings of the IEEE, vol. 91, no. 8, pp. 1247-1256, 2003.
[8] J. M. Daisey, W. J. Angell, and M. G. Apte, "Indoor air quality, ventilation and health symptoms in schools: an analysis of existing information," Indoor Air, vol. 13, no. 1, pp. 53-64, 2003.

[9] F. Salamone, L. Belussi, L. Danza, T. Galanos, M. Ghellere, and I. Meroni, "Design and development of a nearable wireless system to control indoor air quality and indoor lighting quality," Sensors, vol. 17, no. 5, p. 1021, 2017.

[10] D. J. Yao, "A gas sensing system for indoor air quality control and polluted environmental monitoring," in 2009. IEEENANO 2009. 9th IEEE Conference on Nanotechnology, pp. 806-811, Genoa, Italy, July 2009.

[11] A. Schütze, T. Baur, M. Leidinger et al., "Highly sensitive and selective VOC sensor systems based on semiconductor gas sensors: how to?," Environments, vol. 4, no. 1, 2017.

[12] M. Leidinger, T. Sauerwald, C. Alépée, and A. Schütze, "Miniaturized integrated gas sensor systems combining metal oxide gas sensors and pre-concentrators," Procedia Engineering, vol. 168, pp. 293-296, 2016.

[13] M. Penza, O. Hertel, A. L. Spetz, and U. Quass, "New sensing technologies and methods for air pollution monitoring," Urban Climate, vol. 14, p. 327, 2015.

[14] S. Saad, A. Andrew, A. Shakaff, A. Saad, A. Kamarudin, and A. Zakaria, "Classifying sources influencing indoor air quality (IAQ) using artificial neural network (ANN)," Sensors, vol. 15, no. 5, pp. 11665-11684, 2015.

[15] Y. Jiang, K. Li, L. Tian et al., "MAQS: a personalized mobile sensing system for indoor air quality monitoring," in Proceedings of the 13th international conference on Ubiquitous computing, pp. 271-280, ACM, Beijing, China, 2011.

[16] J. Kang and K.-I. Hwang, "A comprehensive real-time indoor air-quality level indicator," Sustainability, vol. 8, no. 9, p. 881, 2016.

[17] W. Device, Air Quality Egg Shop, August 2017, https://shop .wickeddevice.com/product-category/air-quality-egg/.

[18] HSE, What Is the Minimum/Maximum Temperature in the Workplace?, June 2017, http://www.hse.gov.uk/temperature/ faq.htm.

[19] UNISON, Temperature at Work, UNISON, London, 2014.

[20] A. V. Arundel, E. M. Sterling, J. H. Biggin, and T. D. Sterling, "Indirect health effects of relative humidity in indoor environments," Environmental Health Perspectives, vol. 65, pp. 351361, 1986.

[21] D. A. McIntyre, "Response to atmospheric humidity at comfortable air temperature: a comparison of three experiments," The Annals of Occupational Hygiene, vol. 21, pp. 177-190, 1978.

[22] HSE, The Six Basic Factors, June 2017, http://www.hse.gov.uk/ temperature/thermal/factors.htm.

[23] EPA, What Are the Air Quality Standards for PM?, August 2017, https://www3.epa.gov/region1/airquality/pmaq-standards.html.

[24] European Commission, Air Quality Standards, August 2017, http://ec.europa.eu/environment/air/quality/standards.htm.

[25] M. C. Turner, D. Krewski, C. A. Pope 3rd, Y. Chen, S. M. Gapstur, and M. J. Thun, "Long-term ambient fine particulate matter air pollution and lung cancer in a large cohort of never-smokers," American Journal of Respiratory and Critical Care Medicine, vol. 184, no. 12, pp. 1374-1381, 2011. 
[26] A. Delia, Total Volatile Organic Compounds (TVOCs) in the Air, MI, Mt Pleasant, 2012.

[27] OSHA, Indoor Air Quality Investigation, June 2017, https://www.osha.gov/dts/osta/otm/otm_iii/otm_iii_2.html.

[28] Cashins \& Associates, VOCs and Indoor Air Quality, June 2017, http://blog.cashins.com/blog-0/bid/194114/VOCs-andIndoor-Air-Quality.

[29] HSE, General Hazards of Carbon Dioxide, June 2017, http://www.hse.gov.uk/carboncapture/carbondioxide.htm.

[30] OSHA, Carbon Dioxide Exposure Limits and Health Effects, August 2017, https://www.osha.gov/dts/chemicalsampling/ data/CH_225400.html.

[31] EPA, Carbon Monoxide's Impact on Indoor Air Quality, June 2017, https://www.epa.gov/indoor-air-quality-iaq/ carbon-monoxides-impact-indoor-air-quality.

[32] S. W. Ryter and A. M. K. Choi, "Carbon monoxide in exhaled breath testing and therapeutics," Journal of Breath Research, vol. 7, no. 1, pp. 017111-017111, 2013.

[33] EPA, NAAQS TableAugust 2017, https://www.epa.gov/ criteria-air-pollutants/naaqs-table.

[34] Lexis Nexis, Making Light Work - Minimum Light Levels, June 2017, https://www.healthandsafetyatwork.com/content/ making-light-work.

[35] Y. Al horr, M. Arif, M. Katafygiotou, A. Mazroei, A. Kaushik, and E. Elsarrag, "Impact of indoor environmental quality on occupant well-being and comfort: a review of the literature," International Journal of Sustainable Built Environment, vol. 5, no. 1, pp. 1-11, 2016.

[36] K. W. Mui and L. T. Wong, "A method of assessing the acceptability of noise levels in air-conditioned offices," Building Services Engineering Research and Technology, vol. 27, no. 3, pp. 249-254, 2006.

[37] HSE, Controlling Noise at Work, Health and Safety Executive, London, 2015.

[38] Air-Now, International Air Quality, June 2017, https:// airnow.gov/index.cfm?action=airnow.international.

[39] DigiKey, Battery Life CalculatorJuly 2017, https://www.digi key.co.uk/en/resources/conversion-calculators/conversion-cal culator-battery-life.

[40] DOSH, Industry Code of Practice on Indoor Air Quality, June 2017, http://www.dosh.gov.my/index.php/en/osh-info2/chemical-issues-sp-265/343-indoor-air-quality.

[41] A. Steinemann, "Ten questions concerning air fresheners and indoor built environments," Building and Environment, vol. 111, pp. 279-284, 2017. 


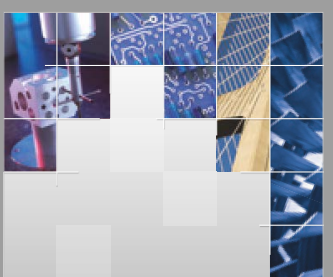

\section{Enfincering}
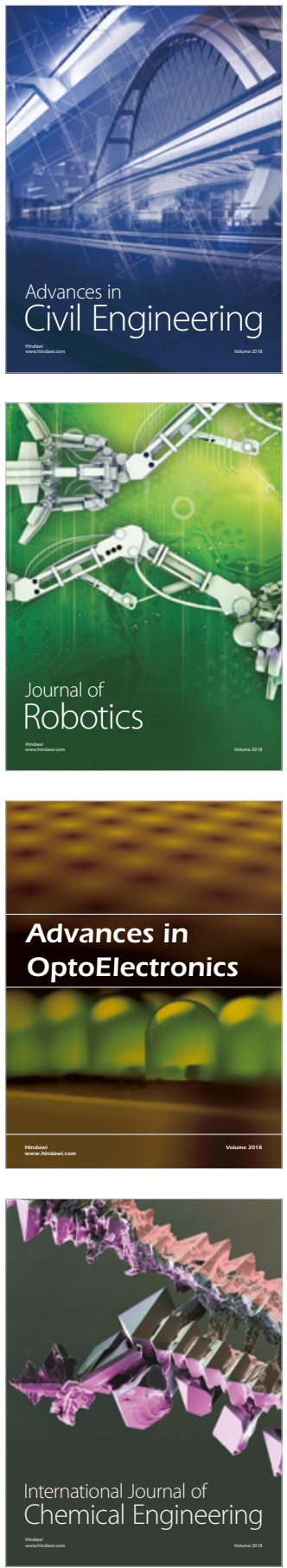

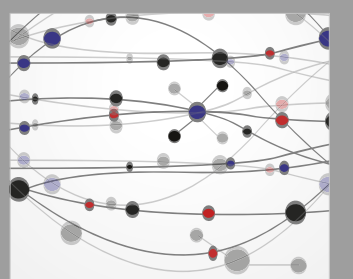

\section{Rotating \\ Machinery}

The Scientific World Journal

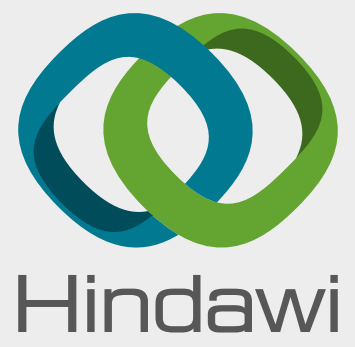

Submit your manuscripts at

www.hindawi.com
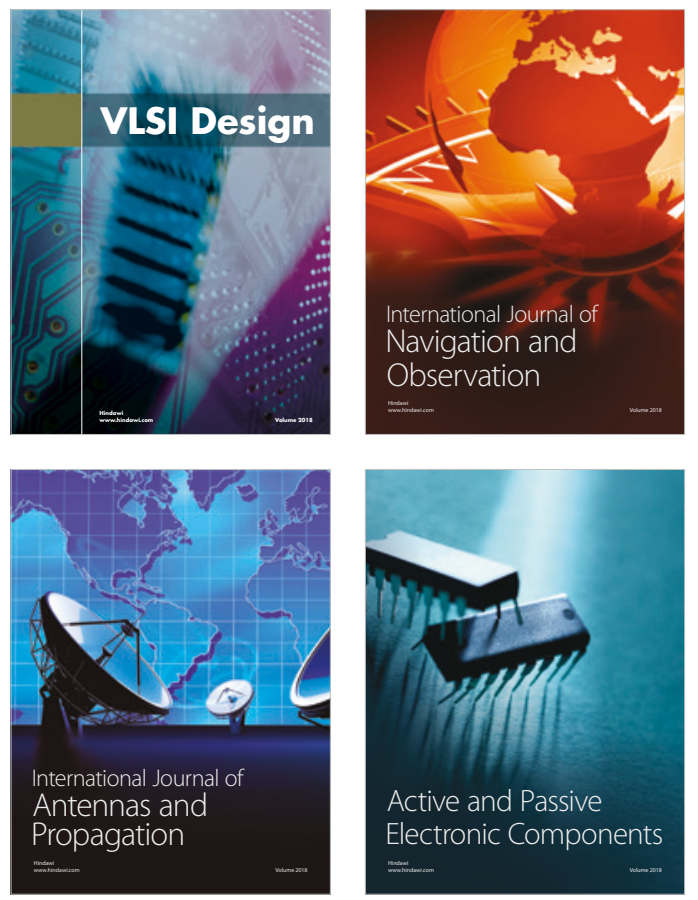
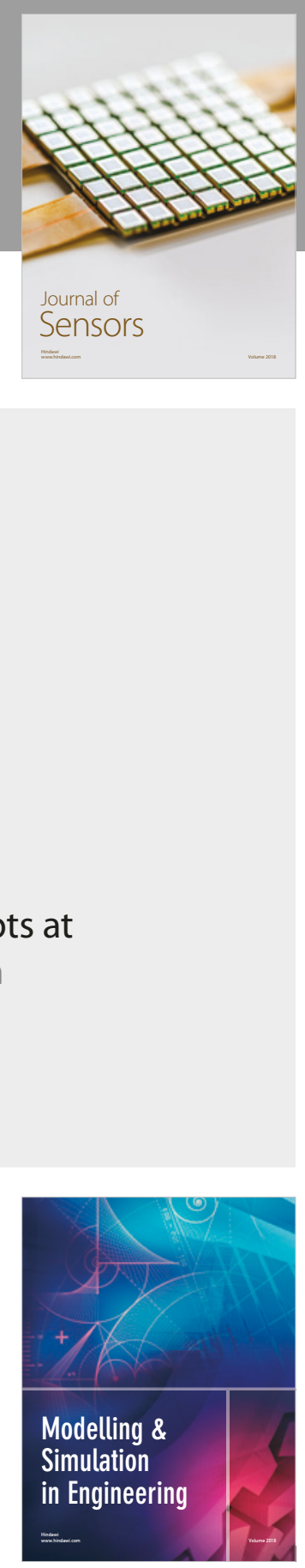

\section{Advances \\ Multimedia}
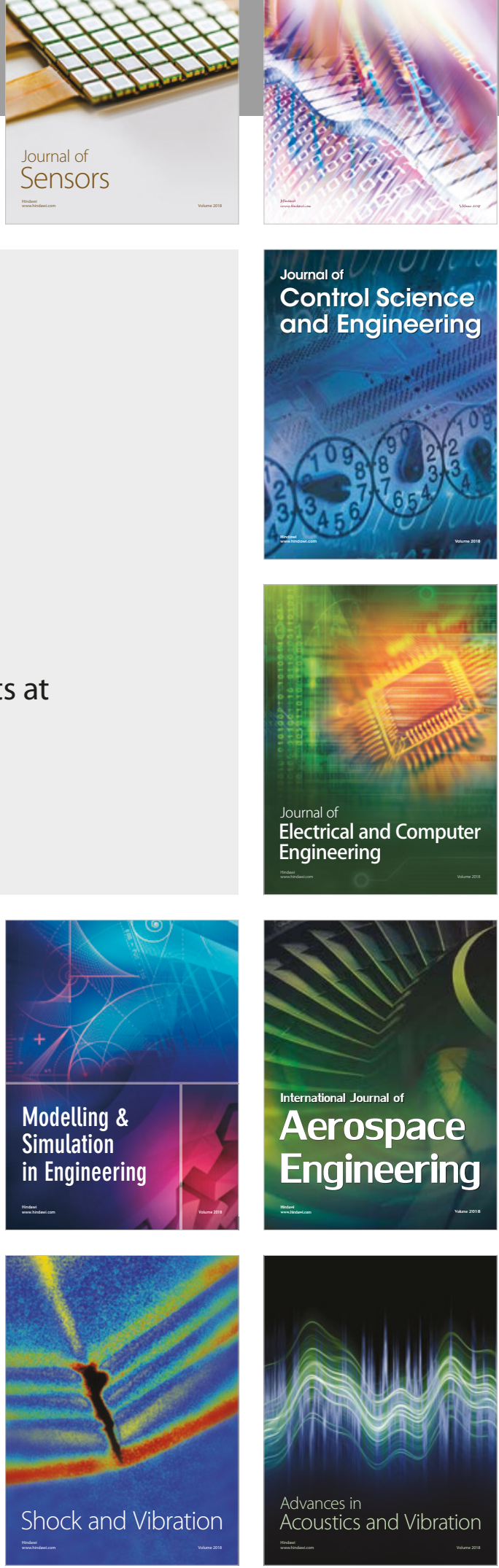